\title{
Non-Verbal Communication in the Modern World
}

\section{Marina Robertovna Gozalova}

PhD in Sociology Associate Professor

Magomed Gazilovich Gazilov

Professor of Philology

\section{Olga Victorovna Kobeleva}

PhD in Psychology Associate Professor

Maria Igorevna Seredina

PhD in Sociology Associate Professor

\section{Elena Sergeevna Loseva}

PhD in Cultural Studies Associate Professor

Russian State University of Tourism and Service

141221, Moscow region, Pushkinski district, Cherkizovo, Glavnaya Street 99

\author{
Doi:10.5901/mjss.2016.v7n4p
}

\section{Abstract}

This article is devoted to the subject of non-verbal communication in English-speaking countries. In the first part of this article we analyze the theoretical issues as Communication Theories in Linguistics and Psycholinguistics, as well as Perception Theory and Non-verbal and Verbal communication in general. Comparative analysis of specify for non-verbal communication with the example of English-speaking countries such as the USA, the UK, Australia, Canada, India, New Zealand is shown in the second part. The main conclusion is that in spite of the fact that these countries are English speaking they have both similar and different non-verbal communication signs and all these differences depend on various cultural contexts, mentality as well as the perception of non-verbal signs. The main idea of this article can be valuable for the world of Psycholinguistics and modern communication because it shows all the important cues of non-verbal communication which every time helps in communication act.

Keywords: intercourse theory, communication theory, perception, verbal communication, non-verbal communication, speech activity.

\section{Introduction}

Communication as a field of scientific knowledge has a long history. Problems in the study of communication processes are among the most pressing problems for mankind. Central position in the history of human communications explains why the various branches such as anthropology, art, education, ethnology, history, journalism, law, linguistics, philosophy, political science, psychology and sociology gravitates to the study of communication processes, says a leading theorist of mass communication Erik Barnouw (Culture in Europe, 09.01.15.)

Communication is a social process. It performs a bridging function in society. Communication takes place not only in the social systems but a certain kind of communication maybe typical for animals for example: bird singing, the language of bees and so on. We also use the concept of communication and talk about the set of technical tools, mechanisms such as transportation, telephone signals, computer systems etc. We are interested in human communication in our article. Functions are implemented in the communication process, that are speech acts. Here we note that that the splitting of the communication process like individual acts is conditional. Communication can be allocated only for research purpose and role reversal from the sender to the recipient because communication is 
continuum. This means continuous interaction in the communication process. Here are the functions of messages and communicative acts which are made by R.Dimbleby and G.Burton such as: warning, advice, information, conviction, expression, entertainment (Dimbleby and Burton, 1998). When the communication process is the object of analysis it is convenient to show a model. There are many models in which schematically reproduced its components and functional characteristics. R.Jacobson interpreted this idea as the following - to send the message context of the speaker to the listener we use communication channel and the code as itself. In modern linguistics this model is used to analyze the functions of language in general, as well as to analyze the functioning of the individual unit loads, speech production and text (Gozalova , 2011).The choosing of communication strategies, tactics and communicative act intentions determining of the individual communicative behavior. The point of communication research becomes the individual as the linguistic personality. Communicative personality has its own communicative experience and communicative skills which are used in the process of communication (Rubinshtain, 1982)

\section{Methodology}

The word "communication" is one of the foreign words which is now widely used in Russian language. Language is one of the most important means of communication. But there are differences between such concepts as language and speech. Linguistics units are sounds, morphemes, the words, sentences, phrases. Each unit belongs to a certain level of language. In every language there are rules, regulations or other use of those units.

The term "speech" is used in two senses. Firstly, it means a type of human communicative activity: use of language to communicative with others. It is a particular activity which is shown in sound or writing form. Secondly it is the result of activity (text, article, report etc.)

Thus, the word "language" means the system, the structure and the word speech means activity. Therefore, it is clear that the definition of the word "communication" is appropriate to use such term like "speech". It should be noted that the phrase linguistics communication also exists and it is used as a synonym.

In this research we are going to analyze the relationship between "speech" and "thoughts". There are two types of speech: external and internal. Internal speech is the linguistics process of thinking without of sound and graphic design: internal pronunciation (speech which preserves the structure of external speech but without sound), proper internal speech (which serves as a means of thinking), interning programming means the formation and consolidation of programs in specific units of verbal expression of the whole text.

External speech is the process of speech activity including various mechanisms of encoding and decoding information. External speech is what we really speak, hear, write and read (Caraulov, 1987)

Speech activity as a form of human activity which characterized by focus and consists of several phrases: orientation, planning, implementation and monitoring. Every separate speech activity is performed in accordance with these phases.

Speech communication is studied by scientists, primarily-linguistics, psychology, sociology and philosophy. In most modern research on this problem, communication is determined through the interaction and influence of people. Many authors indicate a close relationship of the term communication and intercourse. Some authors suppose that these concepts are identical and other that they are closely related, overlapping but not identical.

Communication traditionally means the exchange of values (information) between individuals through according to the common symbols system (linguistic signs) (Maslova, 2007).

Speech communication is an intersubjective verbal interaction in society which associates with the various parties, such as material practical and cognitive activity including a number of functional stylistic types (business, general, scientific communication, etc.) (Tupichina, 2005)

Communication is the social process which is based not only on the human social experience but the most important role plays the linguistic experience during his life (Borozina, 1998). Intercourse and Communication Theories are analyzed as the main parts of our article.

\section{Results}

Intercourse is a complex of multi process of establishing and developing contacts between people, creates the needs for joint action and touches upon the informational exchange, elaboration of interactive strategy as well as presentation of personal thoughts and comprehension of the thoughts and feelings of other people (Psychological dictionary in brief dictionary, 1995). Non-verbal contacts can be characterized:

- visual types of communication are gestures, body language, posture (pantomime), skin reaction (redness, 
pallor, sweating), spatial-temporal organization of communication, eye contact;

- $\quad$ an acoustic system which includes the following aspects: paralinguistic system (voice timbre, range, tone) and extra linguistic system (includes speech pauses and other means such as coughing, laughing, crying, etc.);

- $\quad$ a touch system (touching, kissing and hugging);

- $\quad$-The olfactory system (pleasant and unpleasant odors of environment, artificial and natural human odors).

Objectives of communication reflect the needs of joint activities of people. The following types of interactions: group interaction (cooperation, join labor), competition (rivalry), conflict. To communicate effectively we must comply with certain conditions: equality of so cial position, equality of psychological position, equality in leading active communicative role of interlocutor. Specify of interaction is that each participant retains its autonomy and self-regulation may provide their communicative actions. Non-verbal communication is better known as the language of posture and gestures, includes all forms of expression rights, which are not based on the words (Luria, 1999). In modern psychology there is an opinion that non-verbal cues understanding is one of the most important for productive contacts; non-verbal cues allow us to imagine the real senses and ideas of speakers; the first impression makes us form the opinion about the speaker so it is surely connected with non-verbal processes as a style of walking, face features and peculiarities, eyes, demeanor, style of clothing.

Great importance of non-verbal cues in business communication is supported by experimental studies that say that word disclose only $7 \%$ of meaning, sound, $38 \%$ of values are sound and intonation and $55 \%$ - posture and gestures.

Non-verbal communication includes five subsystems: spatial subsystem (interpersonal space), sight (eye contact), optic-kinetic subsystem which touches upon the person clothing, body language (face expression), pantomimic (posture and gesture). Paralinguistic comprise vocal voice quality, voice band, tone, timbre. So, extra linguistic or nonverbal research examines the speech style, laughter, pause and everything which is connected with personal perception.

There are two disciplines which study means of non-verbal communication they are "Kinesics" and "Proxemics". "Kinesics" includes face expression, gestures, posture and eye contact. These components have large information load. The most illustrative cases when people speak in different languages Kinesics. Gestures then become the only possible means of communication and perform purely communicative function. As for Proxemics it includes the distance between the communicants during speech communication determined by nature of their relationship (intimate/formal, intimate/public). "Kinesics" and "Proxemics" meanings can serve as markers of individual phases of verbal communication (for example, handshake, welcome, farewell kiss, uncap etc.) (Bart,1989).

We can say that a face features and expressions, the position of the body and different body movements are all important parts of the communication process. The non-verbal part of each and every communication process is more important than the verbal dimension. Researches in this sphere point that more then $93 \%$ of all verbal contacts are extremely connected with non-verbal factors. Of cause we can find cultural preconditions of many nonverbal featres (Culy, 1994). A lot of facts of miscommunication follow the lack of cultural knowledge. A person from one cultural field uses special movements and body combinations that have positive meanings in this culture, but they can be opposite in another one. The non-verbal contact in international communication may be difficult. Studying non-verbal distinctions of different cultures is extremely essential according to the contemporary tendency of cross cultural policy and global international communication development. This article is focused on the research of the essential distinctions of several modern cross-cultural contacts from the point of non-verbal research.

\subsection{The role of non-verbal communication}

Non-verbal expressions play the great role in the dialogue. There is a psychological difference between words and visual perception, people usually believe in the visual pictures but not in speech (it happens very often without psychological analysis, by chance). In modern researches they determine five important reasons (or factors) of such preferences: clusters, congruence, context, consistency and culture - These reasons explain that non-verbal language and researches in this sphere is not just about learning body signs and gestures; the most important is the right interpretation of visual picture (Goman,2008). Context is connected with the conditions and reasons of the communication. Clusters of nonverbal cues also play the great role in the interpretation of body language: each simple hand movement can have several interpretations and for the truthful meaning it's necessary to take in attention all the non-verbal reasons (or factors) (Goman, 2008). Congruence pays attention as to the verbal message so non-verbal procedures because when ideas and speech are simultaneous (it happens, when people say true), it is confirmed with typical body signs. Body signs and look are united with discourse (Goman, 2008). Traditions and customs influences a lot on all non-verbal contacts. Here are some types of non-verbal communication: space, eye contact, the appearance of the interlocutor, face expression, greetings, gestures, tone, tempo and voice's volume. 
The individual space refers to the unique style of greeting unknown. Conservative traditions are based on nonphysical contact it means that people of conservative culture greeting people try to keep far from unknown person.

The traditional distance which is typical for this or that culture is extremely significant as it is the right way to prove your respect and show the politeness to the representative of another culture. Different cultures have different customs and it means that even the space of comfort is not the same. Of cause such special zone-features are connected with history and human evolution/ We all change but we keep our nature instincts in our mind.

\subsection{Four types of distance}

We point out four main types of distance (or zone-types) where the first one, the human distance is too close to the body $(0-45 \mathrm{~cm}$.). The second is the individual zone (relatives or people who we trust) the distance is $75-120 \mathrm{~cm}$ (the more intimate person means the shorter distance). The zone of society (acquaintances) is rather farther then the previous one $(120-150 \mathrm{~cm})$. The public area is the farthest one $(300 \mathrm{~cm}$. and more). In everyday life people are usually located in the last zone. All these zones can be different because of cultures and traditions of different societies and breaking the individual zone is negative for the future contact.

We should point out another important non-verbal behavior - touch. It can be used to communicate familiarity, sympathy, affection and other emotions. Touches may be different for example in the workplace people may touch their college to communicate non-verbally. The social-polite touch is handshake. The friendship touch shows that one values another as a person (Lewis, 2006).

On of the most important things in all types of visual discourse is the look. Long eye contact can express assurance and truthful purposes, but in the customs of several nations long looking at a person is extremely rude. Looking straight into the eyes (face to face) can mean assurance, interest, agreement and esteem. But there is another opinion, that looking into the eyes (or "staring at" in this case) can show diffidence and shame, and sometimes it can show really negative thoughts and clear up such emotions as neglect, disregard and even scorn. Fleeting glance can at the same time express haughtiness and arrogance.

The appearance of the interlocutor includes clothes, hairstyle and accessories. All this create the first impression of the person. At first meeting with a new person our appearance is the only source of information.

Face expression is the most important source of information about a person, especially about her/his feelings. Mimic reaction of the interlocutor shows us his emotional response and serve as a means of regulating the communication process.

Greeting people when you meet them for the first time is a key to the future communication. There are some cultures that let to touch and even hug each other when greeting. There are cultures which embraces touching unacceptable.

For example, hand signs are essential in the nonverbal communication and we know the practical examples when gesture explains everything without words. The main role of gestures is to accentuate the phrase or just one word. In this case, congruence is the most essential part of unity of non-verbal contact and oral communication. It helps to strengthen the speech with appropriate body signs.

Voice is an important means of expressing a whole range of subjunctive feelings and meanings. The tone of speech can say a lot about emotional state of the person.

Non-verbal communication is the key factor for all communication process. It is very useful for many reasons to know the mechanisms: it sets up the connections and improves the relations, it helps us to understand better what people feel and think (Gozalova, 2012).

\section{Discussion}

The British are famous as undemonstrative; they keep their emotion hidden from public view not to make anyone comfortable. The nature of the British is emphasized by their respect toward personal space. It is valued by them and in order to feel comfortable. Keeping an acceptable distance is advised. Another thing that during the conversation the British prefer to stand next to each other rather than opposite. British culture also avoid physical contact expect for the handshake, other forms of touching behavior which is irrelevant in business relations (Panfilova, 2004). Men should not allow contacting with women. Touching, hugging and kissing are usually used in family and with very close friends. As for eye contact, British have a tendency to keep it relatively short, as it can certain misunderstanding between people and direct contact may be mistaken for hostility and aggressiveness. If you are talking to a group, then make eye contact with all people and do not focus your attention on one person alone. Next point is that one should not ignore is clothing. 
Conservative dress is the norm for both men and women in the British culture has darker colors such as black, dark blue, grey as wool predominate. The style of outfits depends on the profession. Civil servants, lawyers and accountants wear traditional formal suits, like an example here we note that people in advertising trends to put on something rather more flamboyant, though still stylish. Informal clothing is not appropriate even during leisure activities. The language of gestures in Britain is not frequently used and only the most basic gestures are used. Overdoing a gesture can sometimes come across as the aggressive behavior. There are some gestures that Englishmen use: the index finger is used to point something. One more is two persons holding hands indicate a romantic relationship. Paralanguage is concerned; the British speak in low tone without raising the voice. It is not polite to interrupt persons and intonation conveys one has finished speaking. In British the voice normally goes down at the end of affirmative sentences (Sossur, 1990)

The United States of America have a lot of similarities with Great Britain's non-verbal cues. Less space in the American culture may be associated with either greater intimacy or aggressive behavior. When they are listening to another person, they look almost constantly at the speaker's eyes. In the USA women's clothing more decorated and they obsessed with dress and personal attractiveness while men clothing is more functional (Sossur, 1990). In the American cu lture the smile is typically an expression of pleasure. Many Americans smile freely in public places. American men hide grief or sorrow and scratching the head means three different things: thinking, being confused or skeptical. To talk about first meetings a regular handshake is acceptable. Light hugs are common between good friends and family. They often raise their arm and waggle it back from. It is the sign of saying "hello" or "goodbye" or if they want to get someone's attention. In the USA there are stereotypes about what are considered to be masculine and feminine voices. Masculine voice is expected to be low-pitched and load with moderate to low intonation. Feminine voice is expected to be higherprinted, softer in volume more expressive. Differences in cultural context, mentality as well as perception of non-verbal signs influence on the value of non-verbal signs (Knapp, 1978).

\section{Conclusion}

Having analyzed different studies of linguistics and psycholinguistics in theoretical part we have reached the main goal of this article: indentify features in the perception of non-verbal communication in the frame work of this article. We found out that in spite of the fact that that these countries are English-speaking they have both similar and different non-verbal communication signs. The results are the following: intercourse is a complex of multi process of establishing and developing contacts between people, creates the need for joint action and it has the development of a common strategy of interaction and the exchange of information, perception and understanding of the other person. In this article, communication is shown like the transfer of the information by means of signs and sign systems, so in communication process usually distinguish verbal and non-verbal communication. Verbal is carried out by speech communication. Nonverbal communication is carried out by wordless cues between people and includes: visual types of communication, acoustic system, touch system, the olfactory system. This article can be valuable for studying psycholinguistics and modern communication because it shows all the important cues of non-verbal communication which will help during communication.

\section{References}

Borozina G.V. (1998) Psychology of business communication, Moscow., chapter 7

Bart R. (1989) Selected works. Semiotics. Poetics, Moscow., p.616

CulyCh (1994) Non-Governmental Organization, Moscow., p. 379

Caraulov U.N. (1987) The Russian language and linguistic identify, Moscow "Science", p.264

Culture in Europe 09.01.15. http://www.ipk.ru/index.php?id=2897

Dimbleby R.(1998) Burton G., More than Words. An Introduction of Communication,p.283

Goman C.K.(2008)The Nonverbal Advantage: Secrets and Science of Body Language, chapter 1,p.11

Goman C.K.(2008)The Nonverbal Advantage: Secrets and Science of Body Language, chapter 2,p.21

Gozalova M. R.(2011) Technology of teaching Bachelors foreign language in tourism and hospitality (competence-based approach).Collection of scientific papers, XIII international scientific - practical conference "Tourism and Service: training, problems and prospects of development", Moscow

Gozalova M. R. (2012)Communicative approach to teaching a foreign language (English); The second Release of the publications "Pedagogy in the modern school" Association of non-profit educational organizations in the regions of Russia, Moscow

Knapp M.L. (1978) Non-verbal communication, Moscow., p.49

Lewis, Richard D.(2006) When the cultures collide: leading across cultures, p. 179-194, 205-214,434-440

Luria A.R.(1999)The evolution of the psyche. Selected psychological works, Moscow., p. 411

Maslova A.U. (2007) Russian words in the context of integration process, p.11 
Panfilova A.P. (2004) Business communication in professional activity, Saint-Petersburg, p.34

Psychological dictionary in brief dictionary (1995), Moscow., p.193

Rubinshtain S.L. (1982) Theoretical questions of psychology and the problem of personality, Moscow., p.82

Sossur F. (1990) Notes on general linguistics, Moscow., p.37

Sossur F. (1990) Methodological foundations of social interaction of ethnic groups in the modern megapolicies. Published: National interests: priorities and security, Moscow

Tupichina I.N. (2005) Verbal communication: personal cognitive measure, Moscow.:RGSU, p.131 